\title{
The quality and adequacy of care received at home in the last 3 months of life by people who died following a stroke: a retrospective survey of surviving family and friends using the Views of Informal Carers Evaluation of Services questionnaire
}

\author{
Amanda J. Young MSc BSc (Hons), Angie Rogers MSc BSc and Julia M. Addington-Hall PhD Hon MFPH \\ School of Nursing and Midwifery, University of Southampton, Highfield, Southampton SO17 1BJ, England
}

\author{
Correspondence \\ Amanda Young \\ School of Nursing and Midwifery \\ University of Southampton \\ Highfield, Southampton SO17 1BJ \\ UK \\ E-mail: ajy5@soton.ac.uk
}

\begin{abstract}
Stroke is the third leading cause of death in the UK. Despite this, little is known about the care needs of people who die from or following a stroke. In early 2003, a total of 183 questionnaires were returned from a survey of 493 people who had registered a stroke-related death in four Primary Care Trusts, giving a response rate of $37 \%$. This paper reports on 53 deceased from the survey who had lived at home during their last 3 months and who had been ill for more than 1 month. The data were analysed to explore the role of informal carers and the provision of community-based care in the last 3 months of life. Family and friends helped $82 \%$ of deceased with household tasks, $68 \%$ with personal care, $66 \%$ with taking medication and $54 \%$ with night-time care. By contrast, health and social services helped $30 \%$ with household tasks, $54 \%$ with personal care, $20 \%$ with taking medication and $6 \%$ with night-time care. Two-fifths (43\%) of informants had to give up work or make major life changes to care for the deceased, and $26 \%$ of informants found looking after them 'rewarding'. Half (51\%) reported that help and support from health services were excellent or good compared to $38 \%$ for social services. Results from the Regional Study of Care for the Dying indicated that people who died from a stroke in 1990 and their informal carers would have benefited from increased levels of community-based care and enhanced communication with care professionals. Our data suggest that informal carers continue to provide the majority of care for those who die from stroke, despite government initiatives to improve care for stroke patients and frail elderly people. Further research is required to explore best practice and service provision in caring for this group.
\end{abstract}

Keywords: community care, end-of-life care, palliative care, provision of care, satisfaction with care, stroke

Accepted for publication 9 November 2007

\section{Introduction}

Stroke is one of the leading causes of death. The Department of Health has estimated that approximately 110000 people have a stroke each year, and that between $20 \%$ and $30 \%$ of these patients die within a month (Department of Health 2007). A further 10\% are estimated to die within 1 year and another $5 \%$ within 2 years.
In the UK, stroke costs the NHS $£ 2.8$ billion a year in direct costs, $£ 2.4$ billion in informal care costs and $£ 1.8$ billion in income loss and benefit payments. Stroke may be considered to be a chronic condition that affects both the person suffering a stroke and their family members, and which, in addition, may be life limiting. It can also be difficult to predict prognosis in stroke. Although stroke case fatality has been estimated to be between $20 \%$ and $30 \%$, it is difficult to assess what the percentage 
is for the specific stroke subtypes (Bamford et al. 1990, Stevens et al. 2007).

To date, the stroke literature has focused on the rehabilitation and medical treatment of stroke. There is, however, limited research on the end-of-life experiences of stroke patients and the role, if any, of specialist palliative care for this group. Until relatively recently, much of palliative and end-of-life care research has focused on the needs of cancer patients and their families. The Regional Study of Care for the Dying (RSCD) was the first UK study to highlight issues surrounding the quality of care for people who have died from a stroke (Addington-Hall et al. 1995, 1998a). The RSCD indicated that people who die from a stroke would have benefited from increased levels of communitybased care, improved communication with health and social care professionals and improved symptom control. Additionally, this survey suggested that informal carers played an important role in providing physical and health-related care to this group of patients, while formal carers and service providers played a more limited role.

Over the past decade, research has begun to focus more on the end-of-life and palliative care needs of patients with conditions other than cancer (AddingtonHall et al. 1995, Addington-Hall 2005, Mcilfatrick 2006), and current UK policy documents increasingly emphasise the need for palliative care services to be based on need rather than diagnosis (Exley et al. 2005, Mcilfatrick 2006). Despite attempts to increase awareness and broaden the role of palliative care to include care for patients with conditions other than cancer, including stroke patients (Intercollegiate Stroke Working Party 2004), there are still thought to be inadequacies in the treatment, delivery of care, information and communitycare-based provision from palliative care services for these patients (Mcilfatrick 2006).

The National Clinical Guidelines for Stroke emphasise the need for dedicated stroke units, prompt medical intervention for acute stroke and best practice in both hospital and community-based care, alongside integrated and well coordinated care upon discharge from hospital. However, evidence from the National Sentinel Stroke Audit (Intercollegiate Stroke Working Party 2005) suggests that specialist treatment is lacking, and the delivery and coordination of stroke care are inadequate with only half of hospitals in England having developed protocols for working with community-based health and social service care providers. The recent National Sentinel Stroke Audit (Intercollegiate Stroke Working Party 2007) suggests that despite progress in the development of specialist stroke services, one of the most common complaints of patients is the lack of assistance when they leave the hospital. The audit reported that there are still one quarter of stroke teams without a designated social worker and over a quarter of hospitals do not have a senior nurse specialist. This is likely to have a direct impact on the care provided and information available for those who have had a stroke and live in the community. A high proportion of stroke patients are largely dependent in the first 6 months following stroke for physical and health-related care tasks such as washing, dressing and toileting (Wolfe 2000, Mold et al. 2003). However, studies have revealed that family members often bear the brunt of care and receive limited or inadequate care or support from health or social care professionals (Mold et al. 2003, Murray et al. 2003, O'Connell \& Baker 2003).

The aim of this paper was to assess the level of need and service provision for people who were registered as having died from a stroke and had lived at home during the last 3 months of their life. In particular, we compare our findings to those of the RSCD to assess whether policy guidance and implementation have affected the type of assistance, and the level or degree of help from professional services provided to this group of patients and their families.

\section{Methods}

The analysis presented in this paper was based on data from a subsample from a population-based survey of deaths from stroke in South London in 2002. The methods for the full survey are described here (Addington-Hall et al. 2006a).

\section{Post-bereavement questionnaire}

The Views of Informal Carers Evaluation of Services (VOICES) questionnaire was initially developed following completion of the RSCD (Addington-Hall \& McCarthy 1995), and was based on the interview schedule used in that study. It has been shown in a randomised controlled trial to be an acceptable alternative to interviewer-administered questionnaires in studies of end-of-life care (Addington-Hall et al. 1998b). More recently, the VOICES questionnaire has been extensively revised and tested as part of the PROMOTE study to ensure that it reflected issues of current importance to patients and families, and to incorporate advances in survey research (Aspinal et al. 2003, 2006). For the current study, a stroke-specific version of VOICES was developed. Twenty-one health and social care professionals, and six bereaved carers were asked to identify issues which they felt were important to measure at the end of life in stroke and were missing from the VOICES questionnaire. A literature search was also conducted. This information was used to develop a stroke-specific version of the VOICES questionnaire 
which had nine sections: help at home, general practitioners (GPs), nursing and residential home care, last hospital admission, symptoms and treatment, care in the last 3 days of life, circumstances surrounding death, demographic information and views on completing the questionnaire. In order to identify the level of need of the deceased, an adapted form of the Barthel Activities of Daily Living (ADL) Index was included in the questionnaire (Sulter et al. 1999, Hsueh et al. 2002). The Barthel ADL Index is a widely used assessment tool for seeking information and monitoring geriatric patients' ADL (Ranhoff \& Laake 1993).

\section{Survey methods}

The Office for National Statistics (ONS) drew a sample of deaths registered in four Primary Care Trusts in London in which stroke was given as the main or underlying cause of death. All the deaths had been registered 3-9 months prior to the sample being drawn. The ONS wrote to the person registering an appropriate death (the informant) inviting them to take part in the study in early 2003. The initial mailing contained a letter of invitation, a participant information sheet, a copy of the VOICES II questionnaire, a refusal form and a free-post envelope. Both the questionnaire and the non-response form had a unique identification number. Informants were invited to complete the questionnaire and return it in the free-post envelope; if they did not want to participate, they could either return the non-response form or telephone the research team. If the informant felt that they were not the best person to complete the questionnaire, they were asked to pass it on to whoever they felt appropriate. A consent form was not used, but consent was assumed when participants returned their completed VOICES II questionnaires.

Identification numbers of the returned questionnaires and non-response forms were given to the ONS prior to a second mailing sent approximately 3 weeks after the initial mailing. A reminder letter was sent 3 weeks after this. The local ethics committee gave ethical approval for the study.

The sample size for the full survey was determined from results of the RSCD (Addington-Hall \& McCarthy 1995) which found that $51 \%$ of stroke patients were reported to have had pain control in hospital which controlled the pain partially, if at all. A sample size of 200 completed questionnaires would result in 95\% confidence interval of $44-58$ for the expected proportion of $51 \%$, which was judged to be sufficiently precise for the original survey sample. On the basis of previous VOICES surveys (Addington-Hall et al. 1998a), the reason for having a larger initial sample was to help guarantee a final sample size of at least 200 after non-response.
Data were entered onto SPSS version 14, and this computer software was used to conduct all descriptive and inferential analyses. Descriptive statistics were used to analyse sections of data of the VOICES II questionnaire and unless otherwise stated, the chi-square test was used for all comparisons of the categorical data (statistically significant at $P<0.05$ ). If a $2 \times 2$ table was presented, the continuity for correction value was used, and if any cell had an expected count less than 5, the Fisher's exact test was used. To present data more clearly and to account for the small number of responses of informants for three of the questions related to satisfaction with care and whether personal care needs were met, the response categories were collapsed into two categories rather than reporting each category separately.

\section{Results}

Of the 493 people contacted, 183 returned completed questionnaires, a response rate of $37 \%$. In total, $29 \%$ $(53 / 183)$ of informants reported that the deceased had lived at home during their last 3 months of life and had been ill for more than 1 month. Data for this subsample are used throughout the rest of this paper.

\section{Demographic characteristics}

Informants

Nearly half $(47 \%, 25 / 53)$ informants were the sons or daughters, and $25 \%$ (13) were the spouses or partners of the deceased. Eighty per cent $(42 / 53)$ were aged 50 or over, $67 \%$ (34) were women and $85 \%$ (45) described themselves as white British (Table 1).

\section{The deceased}

Three-fifths of the deceased were aged over 80 and almost one-fifth were over the age of 70 at the time of death. Fifty-five per cent were men (29/53), 81\% (43) of the deceased were described as white British and $41 \%$ $(21 / 51)$ were reported to have lived at home alone. Of the subsample, $9 \%(5 / 53)$ were reported to have spent time in a nursing or residential care home in the 3 months prior to death.

Stroke was the main or underlying cause of death for all those included in the subsample. However, in the 3 months prior to death in response to an open question about any illnesses that the deceased had had such as heart problems, stroke, arthritis, breathing problems or cancer, only $62 \%$ (33/53) of informants reported that the deceased had a stroke or probable stroke. This may have been because the questionnaire was clearly about stroke, so informants did not think they needed to mention this. Eighty-one per cent $(42 / 52)$ of the 
Table 1 Characteristics of the informants $(n=53)$

\begin{tabular}{lc}
\hline Characteristic & $N(\%)$ \\
\hline Informant & \\
Age of the informant ${ }^{\star} \ddagger$ & \\
$30-39$ & $2(4)$ \\
$40-49$ & $9(17)$ \\
$50-59$ & $18(34)$ \\
$60-69$ & $11(21)$ \\
$70-79$ & $9(17)$ \\
$80+$ & $4(8)$ \\
Sex of the informant ${ }^{*} \dagger$ & \\
Male & $17(33)$ \\
Female & $34(67)$ \\
Relationship of the informant to the deceased & \\
Spouse/partner & $13(25)$ \\
Son/daughter & $25(47)$ \\
Brother/sister & $5(9)$ \\
Son-in-law/daughter-in-law & $1(2)$ \\
Parent & $4(8)$ \\
Non-relative & $5(9)$ \\
Ethnic group of the informant $¥$ & \\
White British & \\
White other & $45(85)$ \\
Black Caribbean & $1(2)$ \\
African & $4(8)$ \\
Black other & $1(2)$ \\
Chinese & $1(2)$ \\
\hline
\end{tabular}

* Missing values are included in the final percentage.

$\dagger$ 'Do not know' responses were excluded from the final percentage. $\ddagger$ Percentages rounded up to the nearest whole number.

deceased were reported to have died in hospital, and of these $26 \%(11 / 42)$ had died on a hospital stroke unit. Four-fifths $(78 \%, 39 / 50)$ of informants reported that they felt that the deceased had died in the right place, and two-fifths $(39 \%, 20 / 51)$ reported that they were with the deceased when they died (Table 2).

The subsample reported in this paper did not differ significantly from the rest of the sample in terms of age, relationship of the informant to the deceased or Barthel ADL Index. There were, however, more men $(55 \%, 29 / 53)$ than women in the subsample in comparison to the main study $(39 \%, 72 / 183)$.

\section{Care received at home}

Informants were asked to report about the care the deceased had received at home prior to their death from family/friends, and from health and social services.

\section{Physical and health-related care}

Overall, $87 \%(46 / 53)$ of informants reported that the deceased had received some form of assistance from family and/or friends by comparison to $57 \%$ (30) of
Table 2 Characteristics of the deceased $(n=53)$

\begin{tabular}{|c|c|}
\hline Characteristic & $N(\%)$ \\
\hline \multicolumn{2}{|l|}{ Deceased } \\
\hline \multicolumn{2}{|l|}{ Age of the deceased at death* $† \ddagger$} \\
\hline $50-59$ & $3(6)$ \\
\hline $60-69$ & $6(12)$ \\
\hline $70-79$ & $11(21)$ \\
\hline $80+$ & $32(62)$ \\
\hline \multicolumn{2}{|l|}{ Sex of the deceased } \\
\hline Male & $29(55)$ \\
\hline Female & $24(45)$ \\
\hline \multicolumn{2}{|l|}{ Ethnic group of the deceased ${ }^{*} \dagger \ddagger$} \\
\hline White British & $43(81)$ \\
\hline White Irish & $1(2)$ \\
\hline White other & $2(4)$ \\
\hline Mixed other & $1(2)$ \\
\hline Black Caribbean & $4(8)$ \\
\hline African & $1(2)$ \\
\hline \multicolumn{2}{|l|}{ Domestic arrangement†‡ } \\
\hline Lived alone & $21(41)$ \\
\hline Lived with the informant & $21(41)$ \\
\hline Lived with other people & $12(24)$ \\
\hline \multicolumn{2}{|l|}{ Other illnesses the deceased had $\ddagger$} \\
\hline Heart problems & $20(38)$ \\
\hline Stroke & $33(62)$ \\
\hline Arthritis & $18(34)$ \\
\hline Breathing problems & $12(23)$ \\
\hline Cancer & $8(15)$ \\
\hline \multicolumn{2}{|l|}{ Barthel ADL Index $\ddagger$} \\
\hline 0 & $2(4)$ \\
\hline 1 to 2 & $5(9)$ \\
\hline 3 to 4 & $8(15)$ \\
\hline 5 to 6 & $7(13)$ \\
\hline 7 to 8 & $16(30)$ \\
\hline 9 to 10 & $15(28)$ \\
\hline \multicolumn{2}{|l|}{ Barthel ADL Index $\ddagger$} \\
\hline Difficulty controlling their bladder & $35(67)$ \\
\hline Difficulty controlling their bowels & $28(54)$ \\
\hline Bathing & $44(83)$ \\
\hline Going up and down stairs & $29(55)$ \\
\hline Dressing & $36(68)$ \\
\hline Walking & $33(62)$ \\
\hline Moving on or off a chair or bed & $36(68)$ \\
\hline Eating & $31(59)$ \\
\hline Using the toilet & $34(64)$ \\
\hline Washing, cleaning teeth & $36(68)$ \\
\hline \multicolumn{2}{|l|}{ Place of death* $\dagger$} \\
\hline Home & $8(15)$ \\
\hline Nursing/Residential care home & $2(4)$ \\
\hline Hospital - stroke unit & $11(21)$ \\
\hline Hospital - elderly/geriatric ward & $13(25)$ \\
\hline Hospital - other & $18(35)$ \\
\hline \multicolumn{2}{|c|}{ Were you with the deceased when they died?† } \\
\hline Yes & $20(39)$ \\
\hline No & $31(61)$ \\
\hline \multicolumn{2}{|c|}{ Do you feel that they died in the right place?t } \\
\hline Yes, it was the right place. & $39(78)$ \\
\hline No, it was not the right place. & $9(18)$ \\
\hline Not sure & $2(4)$ \\
\hline
\end{tabular}

${ }^{*}$ Missing values are included in the final percentage.

+ 'Do not know' responses were excluded from the final percentage. $\ddagger$ Percentages rounded up to the nearest whole number. 
Table 3 Assistance with physical and health-related tasks from family/friends and/or health and social services

\begin{tabular}{|c|c|c|c|c|c|}
\hline \multirow[b]{2}{*}{ Type of help } & \multicolumn{5}{|l|}{ Source of help $[N(\%)]$} \\
\hline & $\begin{array}{l}\text { Family and friends, and } \\
\text { health or social services }\end{array}$ & $\begin{array}{l}\text { Family and } \\
\text { friends only† }\end{array}$ & $\begin{array}{l}\text { Health or social } \\
\text { services only }\end{array}$ & Neither† & Total $^{*}$ \\
\hline Personal care & $18(34)$ & $16(30)$ & $9(17)$ & $7(13)$ & $50(94)$ \\
\hline Household tasks & $13(25)$ & $28(53)$ & $2(4)$ & $7(13)$ & 50 (95) \\
\hline Night-time care & 0 & $27(51)$ & $3(6)$ & $20(38)$ & $50(95)$ \\
\hline Taking of medicine & $2(4)$ & $31(58)$ & $8(15)$ & $9(17)$ & $50(94)$ \\
\hline
\end{tabular}

* Percentages rounded up to the nearest whole number.

+ Missing values were not included in the data.

informants who reported that the deceased had received some form of assistance from health and social services with physical and health-related care tasks. Table 3 shows the breakdown of the type of help by the source of help received by the deceased in the last 3 months prior to death.

When asked how much time the informants had spent on these tasks, $58 \%(26 / 45)$ of informants had spent more than $20 \mathrm{~h}$ a week while $9 \%$ (4) spent less than $5 \mathrm{~h}$ a week. (Table 4 )

Fifty-three per cent $(21 / 40)$ of informants reported that the care needs of the deceased were 'always or usually' taken care of as well as they should have been by health and social services. When asked how often the deceased received help from health and social services, $83 \%(25 / 30)$ received help from health and social services 'at least once a day', and 3\% (1) received help 'at least once a month, but not every week'.

Other sources of help and assistance

Informants were asked whether the deceased received any help from other services such as a social worker, home-care worker or meals on wheels. Forty per cent $(19 / 47)$ reported that they received help from a district or community nurse, $21 \%$ (10) from a social worker, $36 \%$ (17) from a home-care worker, $13 \%$ (6) from an occupational therapist and 17\% (8) had meals on wheels. Although informants were asked about Macmillan services, any other nurse at home, Marie Curie nurses and the Stroke Association, contact with these services was minimal (2/47,3/47, $1 / 47$ and $1 / 47$, respectively). Fifty-four per cent $(14 / 26)$ of informants reported that these services worked together as well as they should have done, and that deceased care was well coordinated.

Ninety-two per cent $(47 / 51)$ of informants reported that the deceased had a health problem, which required specialist equipment such as a walking frame and/or stick, bed hoist, wheelchair or commode. Thirteen per cent $(6 / 45)$ of informants reported that it was a big problem getting the specialist equipment.
Table 4 Help, support and satisfaction with care reported by the informant

\begin{tabular}{|c|c|}
\hline & $N(\%)$ \\
\hline \multicolumn{2}{|c|}{ The deceased had problem with* } \\
\hline Communicating & $30(61)$ \\
\hline Speaking & $18(56)$ \\
\hline Reading & $16(50)$ \\
\hline Writing & $18(56)$ \\
\hline Understanding things & $18(56)$ \\
\hline \multicolumn{2}{|c|}{ How much time did family and friends spend on these tasks?* } \\
\hline Less than $5 \mathrm{~h}$ per week & $4(9)$ \\
\hline 5-10 h per week & $8(18)$ \\
\hline 11-19 h per week & $7(16)$ \\
\hline $20+\mathrm{h}$ per week & $26(58)$ \\
\hline \multicolumn{2}{|c|}{$\begin{array}{l}\text { Do you feel that you and your family got as much help and support } \\
\text { from health services as you needed when caring for the deceased?* }\end{array}$} \\
\hline Yes, all the time. & $9(21)$ \\
\hline Yes, some of the time. & $18(43)$ \\
\hline No. & $15(36)$ \\
\hline \multicolumn{2}{|c|}{$\begin{array}{l}\text { Do you feel that you and your family got as much help and support } \\
\text { from social services as you needed when caring for the deceased? }{ }^{*} \dagger\end{array}$} \\
\hline Yes, all the time. & $3(8)$ \\
\hline Yes, some of the time. & $15(38)$ \\
\hline No. & $21(54)$ \\
\hline \multicolumn{2}{|c|}{$\begin{array}{l}\text { Do you feel that the help and support you and your family received } \\
\text { from health services when caring for the deceased wast }\end{array}$} \\
\hline Excellent/Good & $23(51)$ \\
\hline Fair/Poor & $22(49)$ \\
\hline \multicolumn{2}{|c|}{$\begin{array}{l}\text { Do you feel that the help and support you and your family received } \\
\text { from social services when caring for the deceased was } \dagger\end{array}$} \\
\hline Excellent/Good & 15 (38) \\
\hline Fair/Poor & $24(62)$ \\
\hline
\end{tabular}

Communication problems

Three-fifths $(61 \%, 30 / 49)$ of informants reported that the deceased had problems with communication: at least half of the deceased were reported to have had 
problems with speaking $(56 \%, 18 / 32)$, reading $(50 \%, 16)$ and writing $(56 \%, 18)$ (Table 4$)$. Forty-eight per cent $(12 / 25)$ of informants reported that it was a big problem getting help with this compared to $32 \%$ (8) who did not find it a problem. Of those who had communication problems, 32\% (8) of informants reported that health and social services tried hard enough to communicate with the deceased all the time, while 32\% (8) reported that health and social services did not try hard enough.

\section{Level of dependency}

Informants were asked to report on whether the deceased needed help with any ADL. These ADL assessed the level of dependency of the deceased, which was adapted from the Barthel ADL Index. Almost three-fifths $(58 \%, 31 / 53)$ of informants reported that the deceased needed help with seven or more of the 10 ADL compared to less than $10 \%$ (5) who were reported to have needed help with one or two. Eighty-three per cent $(44 / 53)$ of informants reported that the deceased needed help with bathing, and a further 68\% (36) needed help with dressing, moving on or off a chair or bed and washing and/or cleaning their teeth (Table 1).

\section{Satisfaction with care received at home}

Informants were asked whether they felt that family or friends got as much help and support from health and social services as they needed while caring for the deceased prior to their death. For health services, onefifth $(21 \%, 9 / 42)$ felt that they had received sufficient help and support compared to less than one-tenth $(8 \%$, 3/39) for social services (Table 4).

Fifty-one per cent (23/45) of informants reported that the overall help and support family or friends received from health services while caring for the deceased were excellent or good compared to 38\% (15/ 39) who rated social services as excellent or good (Table 4). Seventy per cent $(14 / 20)$ of those who rated health services as excellent or good reported that the personal care needs of the deceased were always or usually taken care of as well as they should have been, compared with $32 \%(6 / 19)$ who rated health services as fair or poor ( $P=0.03$; Fisher's exact test). Similarly, $86 \%$ $(12 / 14)$ of those who rated social services as excellent or good felt that the personal care needs of the deceased were always or usually taken care of as well as they should have been, compared with $38 \%(8 / 21)$ who rated social services as fair or poor ( $P=0.01$; Fisher's exact test).

Although significant associations were found between the age of the informant and health service satisfaction $\left(\chi^{2}\right.$ test $=11.71$; d.f. $\left.=5 ; P=0.04\right)$, more than $83.3 \%$ of cells had an expected count of less than 5 . The age categories were therefore combined (30-49, 50-69 and $70+)$ to overcome this problem. This, however, resulted in age not being significantly associated with healthcare satisfaction $\left(\chi^{2}\right.$ test $=1.85$; d.f. $\left.=2 ; P=0.40\right)$.

\section{Demands faced by informal carers}

Informants were asked three questions about burden of care: whether it was a problem getting a short break from the deceased; whether they had to make major changes to their life to care for the deceased; and whether they found looking after the deceased rewarding, a burden or both. Fifty-four per cent $(25 / 46)$ of informants reported that they did not need respite care for the deceased, and of the remaining subsample who required respite care $38 \%(8 / 21)$ found it a big problem getting a short break. Forty-three per cent $(22 / 51)$ of informants said that they had to give up work or make major changes in their life to care for the deceased. Twenty-six per cent (10/38) of informants reported that they found looking after the deceased 'rewarding', 3\% (1) found it a 'burden' and 71\% (27) found it 'rewarding and a burden' at the same time.

More than three-fifths $(64 \%, 32 / 50)$ of informants reported that the deceased had not received advice about state benefits that they might have been entitled to. Of these, $58 \%(18 / 31)$ reported that it would have been helpful to have such advice, $23 \%$ (7) reported it would not have been helpful and 19\% (6) did not know.

\section{GP visits}

Informants were asked several questions about contact the deceased had with their GPs prior to death. Forty-nine per cent $(23 / 47)$ of informants reported that the deceased had seen their GP once every 2 or 3 months, $45 \%$ (21) at least once a month, but not every week and less than 10\% (3) saw the GP weekly (Table 5). Eighty-three per cent $(40 / 48)$ of informants reported that it was 'very or fairly easy' to get an appointment with the GP urgently if the deceased needed one. Equally, 81\% (33/ 41) found it 'very or fairly easy' to get the GP to agree to visit the deceased at home in the last 3 months of life.

Less than 10\% (3/50) of informants reported that they 'had no worries or fears to discuss', and a further $14 \%$ (7) 'did not try to discuss' with the GP the condition of the deceased, treatment or tests. Of the remaining informants, 50\% (25/50) discussed these issues 'as much as they wanted', and 18\% (9) did 'discuss them but not as much as they wanted to'. Overall, 67\% (31/ 46) of informants rated the care received by the deceased from the GP as excellent or good.

\section{Discussion}

Despite a lower than ideal response rate, this paper provides useful contemporary data on the last 3 months 
Table 5 General practitioner (GP) contact and GP appointment time with the deceased in the last 3 months prior to death

\begin{tabular}{lc}
\hline GP visits in the last 3 months of life & $N(\%)$ \\
\hline How often did the GP see the deceased ${ }^{*}$ & $3(6)$ \\
At least once a week & $21(45)$ \\
At least once a month, but not every week & $23(49)$ \\
Once every 2 or 3 months & \\
If the deceased needed an appointment with a GP urgently, how \\
easy was it to get one?* \\
Very easy & $17(35)$ \\
Fairly easy & $23(48)$ \\
Fairly difficult & $5(10)$ \\
Very difficult & $3(6)$
\end{tabular}

If the GP visited the deceased at home in the last 3 months of life, how easy/difficult was it to get the GP to agree to visit?* ${ }^{*}$ Very easy

Fairly easy

Fairly difficult

Very difficult

$5(12)$

$1(2)$

The deceased wanted the GP to visit but they refused. 2 (5)

Were you able to discuss with the GPs any worries or fears you may have had about the deceased's condition, treatment or tests? $\ddagger$ I had no worries or fears to discuss.

Yes, I discussed them as much as I wanted.

Yes, I discussed them but not as much as I wanted.

$9(18)$

No, although I tried to discuss them.

$6(12)$

No, but I did not try to discuss them.

7 (14)

What do you think about the care the deceased got from their GPs in the last 3 months of life? Would you describe the care as* $† \ddagger$

Excellent

$13(28)$

Good

$18(39)$

Fair

$10(22)$

Poor

$5(11)$

* 'Do not know' responses were excluded from the final percentage. t 'The deceased had no contact with their GP' responses were excluded from the final percentage.

$\ddagger$ Percentages rounded up to the nearest whole number.

of life of people living at home who had died from a stroke. The deaths represented in the overall sample for this survey reflected well the age and sex distribution of people who have stroke in the UK (Carroll et al. 2001). However, the subsample used in this paper is slightly older and includes more deceased men than would be expected, and while all were reported to have been ill for more than a month prior to their death, we do not know when exactly they experienced a stroke or indeed, if they suffered from more than one stroke.

While stroke is acknowledged as a disease from which spontaneous recovery and rehabilitation offer good levels of functional recovery, there is some controversy over the natural progression of such recoveries especially among frail elderly people (Landi et al. 2006). Given the high levels of morbidity, comorbidity and physical and cognitive impairment reported for the majority of this subsample, they could be seen as a group of 'frail elderly people' living in the community who are at increased risk of poor recovery and possibly death following a stroke.

\section{RSCD}

Our key findings do not differ significantly from those of the RSCD despite this survey having been undertaken over 16 years ago. People who go on to die from a stroke and live at home in their last months of life continue to have significant physical and cognitive impairment, and the majority continue to be reliant on informal carers for their personal care and domestic tasks. Substantially, more of the deceased in our study died in hospital than those included in the RSCD, similar numbers died at home and fewer died in nursing or residential homes. While this may to some extent reflect changes in the research methodology, the rise in the number of people dying in hospital and the fall in residential homes may reflect recent changes in statutory care provision that emphasises the right of people to be cared for in their own homes, the provision of complex care packages to people in their own homes and current provision of continuing care in the community. The acute nature of stroke, and its sudden and potentially fatal consequences may account for the low level of home deaths in both surveys. Current best practice encourages rapid hospital attendance and assessment in the event of possible stroke in order that drug-based treatments are administered promptly (Nieuwlaat et al. 2007).

\section{Informal carers}

The research literature indicates that many stroke survivors are dependent on formal and informal support for at least the first 6 months following stroke (Brereton \& Nolan 2000, Healthcare Commission 2006). This may be reflected in our findings; the majority of the deceased were dependent on informal carers, additionally as many as two-thirds may have experienced problems communicating these needs. Nearly half of the informants in this subsample had needed to give up work or make major life changes to care for the deceased. Relatively few felt they were supported by social services as much as they needed with nearly two-thirds describing the help from social services as only fair or poor.

A lack of support from social services may have adverse effects on caregivers (Stoltz et al. 2004). Literature suggests that the transition to a caregiving role is complex and that without adequate preparation or support from healthcare professionals, caregivers are likely to feel the demands of caring (Brereton \& Nolan 2000). However, additional factors such as stroke 
severity, communication problems, lack of a network of services and carers' own health are known to be associated with carers' self-reported strain or burden (Pinquart \& Sorensen 2004, van Exel et al. 2005). Carers are likely to report finding caring a burden if they themselves are depressed. However, stroke severity and carers' prior health are known to be important predictors of caregiver depression (Bugge et al. 1999, Berg et al. 2005).

Although estimated, figures reported from the Census 2000 suggest that one in five carers in the UK who provide a high proportion of care is in poor health (Office for National Statistics 2002, Carers UK 2004, 2005). Research needs to focus on the care provision for carers themselves, and services need to be developed that support carers and in consequence enhance their quality of life (Grant et al. 2000, Elkington et al. 2004, Sit et al. 2004, Mold et al. 2006). Services need to, therefore, build a care package for stroke patients based on their individual needs as well as those of their carers rather than focusing on task-oriented instrumental or 'standard' care and services (Intercollegiate Stroke Working Party 2007).

\section{A need for palliative or supportive care?}

The National Service Framework argues that elderly people in the UK experience poorer access to palliative care services, and this is reflected in our findings, as even among those deceased who were reported to have cancer there was little or no reported contact with specialist palliative care providers. While to date, there is a dearth of evidence concerning the level of need for and potential benefits of specialist palliative care intervention following stroke, our findings indicate that in the last 3 months of life, these patients, in addition to being at an increased risk of death, are likely to experience reduced physical and cognitive capacity and that they are often reliant on informal carers. As such, this sample may constitute a group of elderly people with complex needs, who are often socially isolated and dependent on older or non-resident informal carers. It is noteworthy that the World Health Organization has indicated that these individuals may benefit from specialist palliative care input (World Health Organisation 2004).

The Gold Standards Framework's Prognostic Indicator Guidance is a tool currently advocated as part of the UK End of Life Care Strategy. This tool aims to assist GPs in identifying patients who are likely to die over the forthcoming 6-12 months (Thomas 2003, 2004). The criteria given for patients with stroke or dementia include: urinary and faecal incontinence, Barthel ADL Index of less than three, reduced ability to perform ADL and cognitive impairment. Using these criteria, between half and three-quarters of the deceased in the subsample would have been predicted to die. Had these people been cared for using the Gold Standards Framework, all would have been assessed for benefits that are available to people and their families who are recognised as being in the last 6 months of life. Their care would have been reviewed on a monthly basis by their primary care team to ensure that their care needs were being met. Once identified as having palliative care needs, the deceased and their carers may have had access to additional services such as night sitting, day care, occupational therapy and physiotherapy.

The National Clinical Guidelines for Stroke (2004) states that local services need to identify where expertise in palliative care can be accessed. It is suggested that in both the acute and community sector members of stroke teams should have some training in palliative care skills. However, those involved in caring for stroke patients must be able to identify patients and families who might benefit from palliative care interventions. Patients, their families and healthcare professionals may be reluctant to discuss prognosis or planning for the end of life, but without this, opportunities are missed that may enhance both the quality of life and death for this group (Elkington et al. 2004). More importantly perhaps is the need for education and information for the patient and carer about the management of stroke upon discharge from hospital. At present, many stroke units do not have the resources to manage patients in the community. Consequently, the National Sentinel Stroke Audit (2007) has recommended increased community provision for stroke patients.

\section{Limitations}

Survey methods

The main limitation of the study is the poor response rate. While other surveys using similar VOICES questionnaires have produced response rates of over 40 per cent (Addington-Hall et al. 2006b), none to date have matched the 70 per cent achieved in the RSCD (Addington-Hall \& McCarthy 1995). There may be a number of factors accounting for the low response rate. Changes in the Data Protection Act have meant that informants may now only be contacted via the ONS. The research literature suggests that questionnaires sent by a governmental office are likely to have lower response rates, although our information for informants stressed that the VOICES II questionnaire was being sent on behalf of a university, informants may not have realised this. The small sample size of the subsample of interest might also be seen as a limitation. However, its use has allowed an in-depth analysis of the experience of people who die from stoke and live at home. 
Additionally, the questionnaires were by necessity sent to the person who registered the death, who may not have been the person who knew the most about the end-of-life care of the deceased and who may not have felt able to pass the questionnaire on as invited to.

However, although it was possible to ascertain the number of informants who found the services lacking, it would have been useful to have additional information about what help or support they considered important or needed from the services. This information would have provided a more complete picture for the future development of services for stroke patients, including specialist palliative care services.

\section{The retrospective method}

Some questions have been raised about the use of retrospective proxy accounts in the description of end-of-life care provision. However, the use of the proxy method allows for a whole population of deaths to be sampled and for information relating to the last days or hours of life and care after death and during bereavement to be collected (Higginson et al. 1994, McPherson \& AddingtonHall 2003). Some concerns have been expressed about the validity of such accounts with fears that bereaved relatives may be angry and over-critical or overly grateful and unwilling to criticise care and that their opinions may change over time. There have also been doubts over the validity of proxy accounts in that they may not accurately reflect the experiences of the deceased at the end of life. Current research suggests a reasonably good agreement between patient and proxy accounts for service provision, service use and more concrete symptoms. It also indicates that proxy responses for more subjective responses are based on memories of the patient's experience, rather than simply on the proxy's own distress as had been hypothesised (Addington-Hall \& McPherson 2001, McPherson \& Addington-Hall 2003, 2004).

\section{Conclusion}

People living at home in the last 3 months of life who die from a stroke are largely reliant on informal carers, the majority of whom have had to make major changes to their lives in order to undertake their caring role. Although $67 \%$ of informants rated the care received by the GP in the months prior to death as 'excellent', the majority of care provided by social services was described as fair or poor and at times lacking altogether. To date, there is little evidence of best practice in caring for this group of patients in the community; however, it is obvious that they and their families have high levels of need. While further research is needed to define best practice in this area, at present practitioners should consider the continuing supportive and palliative care needs of this group.

Although our findings cannot be generalised to the wider population of stroke patients, they suggest that this group may have benefited from supportive and/or specialist palliative care input. Further research is therefore needed to determine best practice in this area as well as the needs of the stroke patient and informal carer.

\section{Acknowledgements}

This project was funded by the Department of Health. The authors are grateful to the ONS for their help in running the study.

\section{References}

Addington-Hall J. (2005) Extending palliative care to chronic conditions. European Journal of Palliative Care 12 (2), 14-17.

Addington-Hall J. \& McCarthy M. (1995) Regional study of care for the dying: methods and sample characteristics. Palliative Medicine 9, 27-35.

Addington-Hall J. \& McPherson C. (2001) After-death interviews with surrogates/bereaved family members: some issues of validity. Journal of Pain and Symptom Management 22 (3), 784-790.

Addington-Hall J., Lay M., Altmann D. \& McCarthy M. (1995) Symptom control, communication with health professionals, and hospital care of stroke patients in the last year of life as reported by surviving family, friends and officials. Stroke 26 (12), 2242-2248.

Addington-Hall J., Walker L., Jones C., Karlsen S. \& McCarthy M. (1998a) A randomised controlled trial of postal versus interviewer administration of a questionnaire measuring satisfaction with, and use of, services received in the year before death. Journal of Epidemiology Community Health 52, 802-807.

Addington-Hall J., Lay M., Altmann D. \& McCarthy M. (1998b) Community care for stroke patients in the last year of life: results of a national retrospective survey of surviving family, friends and officials. Health and Social Care in the Community 6 (2), 112-119.

Addington-Hall J., Rogers A., Saleem T. \& Young A. (2006a) Development of a Postal Questionnaire for Use in a Population Based Survey of the Experiences of People Who Die from Stroke and Their Families, from the Perspective of Bereaved Relatives. University of Southampton for Department of Health, London.

Addington-Hall J., Shipman C., Burt J., Ream E., Beynon T. \& Richardson A. (2006b) Evaluation of the Education and Support Programme for District and Community Nurses in the Principles and Practice of Palliative Care. University of Southampton for Department of Health, London.

Aspinal F., Addington-Hall J., Hughes R. \& Higginson I. (2003) Measuring the quality of palliative care: a review of the literature. Journal of Advanced Nursing 42, 324-329.

Aspinal F., Hughes R., Dunckley M. \& Addington-Hall J. (2006) What is important to measure in the last weeks and months of life? A modified nominal group study. International Journal of Nursing Studies 43, 393-403. 
Bamford J., Sandercock P., Dennis M. \& Warlow C. (1990) A prospective study of acute cerebrovascular disease in the community: the Oxfordshire Community Stroke Project. 2. Incidence, case fatality rates and overall outcome at one year of cerebral infarction, primary intracerebral and subarachnoid haemorrhage. Journal of Neurological Neurosurgical Psychiatry 53, 16-22.

Berg A., Palomaki H., Lonnqvist J., Lehtihalmes M. \& Kaste M. (2005) Depression among caregivers of stroke survivors. Stroke 36, 639-643.

Brereton L. \& Nolan M. (2000) 'You do know he's had a stroke, don't you?' Preparation for family care-giving - the neglected dimension. Journal of Clinical Nursing 9, 498-506.

Bugge C., Alexander H. \& Hagen S. (1999) Stroke patients' informal caregivers: patient, caregiver, and service factors that affect caregiver strain. Stroke 30, 1517-1523.

Carers UK (2004) In Poor Health: The Impact of Caring on Health. Carers UK, London.

Carers UK (2005) Older Carers in the UK. Sheffield Hallam University for Carers UK, London.

Carroll K.M.S., Eliahoo J. \& Majeed A. (2001) Stroke incidence and risk factors in a population-based prospective cohort study. Health Statistics Quarterly 12, 18-26.

Department of Health (2007) A New Ambition for Stroke: A Consultation on a National Strategy. Department of Health, London.

Elkington H., White P., Addington-Hall J., Higgs R. \& Pettinari C. (2004) The last year of life in COPD: a qualitative study of symptoms and services. Respiratory Medicine 98, 439-445.

van Exel N., Koopmanschap M., van den Berg B., Brouwer W. \& van den Bos G. (2005) Burden of informal caregiving for stroke patients. Cerebrovascular Diseases 19, 11-17.

Exley C., Field D., Jones L. \& Stokes T. (2005) Palliative care in the community for cancer and end stage cardiorespiratory disease: the views of patients, lay-carers and health care professionals. Palliative Medicine 19, 76-83.

Grant J., Bartolucci A., Elliot T. \& Newman Giger J. (2000) Sociodemographic, physical, and psychosocial characteristics of depressed and non-depressed family caregivers of stroke survivors. Brain Injury 14 (12), 1089-1100.

Healthcare Commission (2006) Survey of Patients 2006: Caring for People After They Have Had a Stroke. Healthcare Commission, London.

Higginson I., Priest P. \& McCarthy M. (1994) Are bereaved family members a valid proxy for a patient's assessment of dying? Social Science \& Medicine 38 (4), 553-557.

Hsueh I., Lin J., Jeng J. \& Hsieh C. (2002) Comparison of the psychometric characteristics of the functional independence measure, 5 item Barthel index, and 10 item Barthel index in patients with stroke. Journal of Neurological Neurosurgical Psychiatry 73, 188-190.

Intercollegiate Stroke Working Party (2004) National Clinical Guidelines for Stroke. Royal College of Physicians, London.

Intercollegiate Stroke Working Party (2005) National Sentinel Stroke Audit 2004. Royal College of Physicians, London.

Intercollegiate Stroke Working Party (2007) National Sentinel Stroke Audit 2006. Royal College of Physicians, London.

Landi F., Onder G., Cesari M., Zamboni V., Russo A., Barillaro C. \& Bernabei R. (2006) Functional decline in frail communitydwelling stroke patients. European Journal of Neurology 13 , $17-23$.
Mcilfatrick S. (2006) Assessing palliative care needs: views of patients, informal carers and healthcare professionals. Journal of Advanced Nursing 57 (1), 77-86.

McPherson C. \& Addington-Hall J. (2003) Judging the quality of care at the end of life: can proxies provide reliable information? Social Science \& Medicine 56, 95-109.

McPherson C.A. \& Addington-Hall, J. (2004) Evaluating palliative care: bereaved family members' evaluations of patients' pain, anxiety and depression. Journal of Pain and Symptom Management 28 (2), 104-114.

Mold F., McKevitt C. \& Wolfe C. (2003) A review and commentary of the social factors which influence stroke care: issues of inequality in qualitative literature. Health and Social Care in the Community 11 (5), 405-414.

Mold F., Wolfe C. \& McKevitt C. (2006) Falling through the net of stroke care. Health and Social Care in the Community 14 (4), 349-356.

Murray J., Ashworth R., Forster A. \& Young J. (2003) Developing a primary care-based stroke service: a review of the qualitative literature. British Journal of General Practice 53, 137-142.

Nieuwlaat R., Olsson S., Lip G., et al. (2007) Guidelineadherent antithrombotic treatment is associated with improved outcomes compared with undertreatment in high-risk patients with atrial fibrillation. The Euro Heart Survey on Atrial Fibrillation. American Heart Journal 153 (6), 1006-1012.

O'Connell B. \& Baker L. (2003) Managing as carers of stroke survivors: strategies from the field. International Journal of Nursing Practice 10, 121-126.

Office for National Statistics (2002) Carers 2000. The Stationery Office, London.

Pinquart M. \& Sorensen S. (2004) Associations of caregiver stressors and uplifts with subjective well-being and depressive mood: a meta-analytic comparison. Aging $\mathcal{E}$ Mental Health 8 (5), 438-449.

Ranhoff A. \& Laake K. (1993) The Barthel ADL Index: scoring by the physician from patient interview is not reliable. Age and Ageing 22, 171-174.

Sit J., Wong T., Clinton M., Li L. \& Fong Y. (2004) Stroke care in the home: the impact of social support on the general health of family caregivers. Journal of Clinical Nursing 13, 816-824.

Stevens T., Payne S., Burton C., Addington-Hall J. \& Jones A. (2007) Palliative care in stroke: a critical review of the literature. Palliative Medicine 21, 323-331.

Stoltz P., Uden G. \& Willmanm A. (2004) Support for family carers who care for an elderly person at home - systematic review. Scandinavian Journal of Caring Sciences 18, 111-119.

Sulter G., Steen C. \& De Keyser J. (1999) Use of the Barthel Index and Modified Rankin Scale in Acute Stroke Trials. Stroke 30, 1538-1541.

Thomas K. (2003) The Gold Standards Framework in community palliative care. European Journal of Palliative Care $\mathbf{1 0}$ (3), 113-115.

Thomas K. (2004) The Gold Standards Framework: A Programme for Community Palliative Care. Macmillan Cancer Relief, London.

Wolfe C. (2000) The impact of stroke. British Medical Bulletin 56 (2), 275-286.

World Health Organisation (2004) Better Palliative Care for Older People. World Health Organisation, Copenhagen, Denmark. 